\title{
Polypharmacy in older adults with human immunodeficiency virus infection compared with the general population
}

\author{
Mercedes Gimeno-Gracia' \\ María José Crusells- \\ Canales $^{2}$ \\ Francisco Javier Armesto- \\ Gómez $^{3}$ \\ Vicente Compaired-Turlán ${ }^{4}$ \\ María José Rabanaque- \\ Hernández ${ }^{5}$ \\ 'Pharmacy Department, Lozano \\ Blesa University Clinical Hospital, \\ Aragon Institute for Health Research, \\ ${ }^{2}$ Department of Infectious Diseases, \\ Aragon Institute for Health Research, \\ Lozano Blesa University Clinical \\ Hospital, ${ }^{3}$ Pharmacy Department, \\ Aragon Health Service, ${ }^{4}$ Pharmacy \\ Department, Lozano Blesa University \\ Clinical Hospital, ${ }^{5}$ Department of \\ Public Health, University of Zaragoza, \\ Zaragoza, Spain
}

This article was published in the following Dove Press journal:

Clinical Interventions in Aging

26 August 2016

Number of times this article has been viewed

Background: The percentage of older HIV-positive patients is growing, with an increase in age-related comorbidities and concomitant medication.

Objectives: To quantify polypharmacy and profile types of non-antiretroviral drugs collected at community pharmacies in 2014 by HIV-positive individuals on antiretroviral therapy and to compare these findings with those of the general population.

Methods: HIV-positive patients ( $n=199)$ were compared with a group of patients from the general population $(n=8,172)$, aged between 50 and 64 years. The factors compared were prevalence of polypharmacy ( $\geq 5$ comedications with cumulative defined daily dose [DDD] per drug over 180 ), percentage of patients who collected each therapeutic class of drug, and median duration for each drug class (based on DDD). Results were stratified by sex.

Results: Polypharmacy was more common in HIV-positive males than in the male general population ( $8.9 \%$ vs $4.4 \%, P=0.010$ ). Polypharmacy was also higher in HIV-positive females than in the female general population $(11.3 \%$ vs $3.4 \%, P=0.002)$. Percentage of HIV-positive patients receiving analgesics, anti-infectives, gastrointestinal drugs, central nervous system (CNS) agents, and respiratory drugs was higher than in the general population, with significant differences between male populations. No differences were observed in proportion of patients receiving cardiovascular drugs. The estimated number of treatment days (median DDDs) were higher in HIV-positive males than in males from the general population for anti-infectives (32.2 vs 20.0, $P<0.001$ ) and CNS agents (238.7 vs 120.0, $P=0.002$ ). A higher percentage of HIV-positive males than males from the general population received sulfonamides ( $17.1 \%$ vs $1.5 \%, P<0.001)$, macrolides (37.1\% vs $24.9 \%, P=0.020)$, and quinolones ( $34.3 \%$ vs $21.2 \%, P=0.009)$.

Conclusion: Polypharmacy is more common in HIV-positive older males and females than in similarly aged members of the general population. HIV-positive patients received more CNS drugs and anti-infectives, specifically sulfonamides, macrolides, and quinolones, but there were no differences in the percentage of patients receiving cardiovascular drugs. It is essential to investigate nonantiretroviral therapy medication use in the HIV-positive population to ensure these patients receive appropriate management.

Keywords: polypharmacy, HIV infection, aging

Correspondence: Mercedes GimenoGracia

Pharmacy Department, Lozano Blesa University Clinical Hospital, C/San Juan Bosco, 50009, Zaragoza, Spain

Tel +34650547519

Fax +34976558095

Email mgimenogrsalud@gmail.com

\section{Introduction}

The mean age of patients with HIV infection is increasing. This is mainly due to increased life expectancy as a result of effective antiretroviral therapy (ART) ${ }^{1,2}$ and, in Spain, there is an increase in the percentage of patients diagnosed at an older age. ${ }^{3}$ The introduction of highly active ART has changed the face of HIV infection by considerably reducing morbidity and mortality, improving quality of 
life, and increasing life expectancy. ${ }^{4,5}$ In a study from the Netherlands, Smit et al predicted that by $2030,73 \%$ of their HIV-positive patients would be aged $\geq 50$ years. ${ }^{6}$ In the context of HIV infection, the term "older" refers to patients aged $\geq 50$ years. $^{7,8}$

The combined impact of HIV infection and the risk of noncommunicable diseases can add to the disease burden of aging HIV-positive individuals. Comorbidities are more numerous and occur at a younger age in this aging population than in the general population; this does not occur in the younger HIV population. ${ }^{9-11}$ The medical management of older HIV-positive individuals brings with it the management of polypharmacy. The problems associated with polypharmacy include worse medication adherence, increased risk of adverse drug events, use of inappropriate drugs, hospitalization, geriatric syndromes, and mortality. ${ }^{12-15}$

Relatively few studies have analyzed the extent of polypharmacy in older HIV-positive individuals or the classes of drugs prescribed or their effects on drug-drug interactions. ${ }^{16-20}$ Furthermore, such studies do not specify treatment doses or duration of long-term treatments and use drug consumption data based on clinical notes and/ or patient self-reports, which are potential sources of bias and errors. ${ }^{21,22}$

A previous study by our team in 2011 analyzed non-ART medication in the HIV-positive population aged $\geq 50$ years, and compared this with the findings in the general population. ${ }^{23}$ Medications were analyzed at the second level of the World Health Organization (WHO) Anatomical Therapeutic Chemical (ATC) classification, and only male patients were compared. The present study included a larger number of HIV-positive patients and a sample of the general population with the same age and sex distribution as the HIV-positive population. Normally, the general population has a more even distribution of age and sex, something that does not occur in the HIV-positive population. This study also included an analysis between females; this was not performed in our previous study from 2011. Furthermore, a more global analysis of medication use was performed, analyzing all drugs used by organ or system, allowing a more comprehensive evaluation.

The purpose of the present study was to determine the prevalence of polypharmacy in older HIV-positive males and females, by analyzing the number and types of drugs dispensed at pharmacies over a year, and to compare our findings with those for a sample of the general population with the same age and sex distribution.

\section{Methods}

We performed a descriptive retrospective study of HIVpositive individuals aged 50-64 years and receiving outpatient ART at a university hospital pharmacy in Aragón, Spain, between January and December 2014. We chose a cutoff age of 64 years because there are relatively few HIV-positive patients older than 64 in the population served by our hospital. In Spain, hospital pharmacies dispense all ART prescriptions to HIV-positive individuals from the surrounding geographic area: in this case, a population of 299,934 . ART is only dispensed in hospital pharmacies, not in community pharmacies. Patients receiving postexposure prophylaxis were excluded from the study, as these patients do not have a diagnosis of HIV.

The study was approved by the Aragón Clinical Research Ethics Committee. Patient consent was not necessary because it was an observational retrospective study, with no intervention. It forms part of a larger project entitled "Antiretroviral therapy in HIV-naïve patients and use of concomitant medication in older HIV-infected patients", which is regulated by the Aragonese Government (Royal Decree 223/2004 and Decree 26/2003, modified by Decree 292/2005).

The reference population was a random sample of 8,172 patients, from a general population of 54,798 aged 50-64 years and from the same geographic area as the HIV-positive population. The age and sex distribution of the general population sample and the HIV population were similar. We calculated the size of the general population sample needed to estimate the proportion of people being treated with each class of drug.

The study variables included patient date of birth, sex, and the following HIV infection-related variables: date of HIV diagnosis, date of ART initiation, HIV plasma viral load (copies/mL), and CD4 cell count at the last study visit, and antiretroviral drugs received at completion of the study period. This information was compiled from medical records and the pharmacy-dispensing program.

Drugs dispensed from community pharmacies defined as those with a medical prescription covered by the public health system and registered in the district-level Aragonese Consumption of Pharmaceuticals Information System, from January 1, 2014 to December 31, 2014, were also collected. The analysis excluded antiretroviral medications, medications that do not require a physician's prescription, medications that do not have a defined daily dose (DDD) such as eye drops and creams, drugs prescribed in the private health care setting, and medicinal plants. Sum of DDD of each drug per patient was calculated. In addition to ethical approval, we 
received permission to access the Aragonese Consumption of Pharmaceuticals Information System Database using an anonymized view.

The proportion of HIV-positive patients and of the general population patients that collected drugs from different therapeutic classes and from each therapeutic subgroup of drugs was compared. A detailed analysis was performed using the therapeutic subgroups, which showed large differences between the HIV-positive patients and general population.

The median duration of treatment for each therapeutic class of drugs and for each therapeutic subgroup in the HIV population and the general population (based on the median DDD of the sum of all drugs within each class) was also compared.

To determine the number of non-ART drugs per patient per year, we used the following conditions: 1) each prescription collected was considered to correspond to one medication taken and 2) long-term treatments were divided into treatments lasting $>90$ days ( $>90 \mathrm{DDD} / \mathrm{drug} /$ patient/year) or $>180$ days $\left(>180 \mathrm{DDD} / \mathrm{drug} /\right.$ patient/year). ${ }^{24,25}$ Polypharmacy was defined as the use of five or more concomitant medications in three possible contexts: drugs with DDD $>1$, DDD $>90$, or DDD $>180$. Five concomitant medications is generally accepted as the threshold associated with negative health outcomes. ${ }^{12,26,27}$

Each drug was assigned to a therapeutic subgroup according to the second level of the 2015 version of the WHO ATC classification system. ${ }^{28}$ Drugs were also classified into six broad therapeutic classes: ${ }^{16}$ analgesics, anti-infectives, gastrointestinal (GI) drugs, central nervous system (CNS) agents, cardiovascular drugs, and respiratory drugs. Subsequently, a detailed analysis was performed of the drugs within the subgroups, which showed a large difference between populations.

We calculated the DDD for each drug taken by each patient during the study year. According to WHO, DDD is "the assumed average maintenance dose per day for a drug used for its main indication in adults", and does not necessarily reflect the recommended or prescribed daily dose. For example, the DDD of amlodipine is $5 \mathrm{mg}$. If a person collects $3005 \mathrm{mg}$ tablets of amlodipine in a year, the DDD/ drug/year is 300; if this person collects $30010 \mathrm{mg}$ tablets of amlodipine, the DDD/drug/year is 600. The DDD is a technical unit of measurement, used in combination with the ATC system that allows the quantification of annual drug consumption and overall comparison of drug use between different populations. The primary purpose of the ATC/ DDD system, as reported by WHO, is to "serve as a tool for drug utilization research in order to improve quality of drug use". The use of DDD was considered to correspond to the duration of treatment, and the calculation of the DDDs in the therapeutic subgroups was performed as follows: all the DDDs for one drug for one patient were added, then the DDDs for all the drugs that make up a therapeutic subgroup in that patient were added, and then the median DDD of this drug group was calculated from all the patients receiving a drug from that group.

Data analysis was stratified by sex, as drug use has been found to differ between males and females..$^{20,26}$

\section{Statistical analyses}

In order to estimate the proportion of individuals in the general population treated with different medications, a sample was taken of the general population aged 50-64 years $(n=54,798)$. This sample had the same age and sex distribution as the HIV-positive population. To calculate the sample size needed, we used a confidence level of $95 \%$, precision of $1 \%$, and an expected proportion of $50 \%$.

Qualitative data are expressed as frequencies and percentages, and quantitative data as medians and interquartile range (IQR) (25th to 75th quartile). Qualitative variables frequencies were compared using the chi-square test, and the means of nonnormally distributed data were compared using the Mann-Whitney $U$ statistic. Analyses were performed using SPSS Version 15.0 (SPSS Inc., Chicago, IL, USA), University of Zaragoza license.

\section{Results}

There were $225 \mathrm{HIV}$-positive individuals $\geq 50$ years who received ART from the hospital pharmacy services, representing $30.7 \%$ of all HIV-positive patients who used this service between January 1 and December 31, 2014. Three individuals received postexposure prophylaxis, and there were 23 individuals $>64$ years. Ultimately, therefore, 199 HIV-positive patients were included in the study.

\section{HIV-positive population description}

The study included 199 HIV-positive patients (73.4\% males) aged 50-64 years. Of these, $66.8 \%$ were aged between 50 and 54 years. The median time since diagnosis was 18 years (IQR, 10.1-24.0), and the median duration of ART was 14.7 years (IQR, 8.2-18.0). At the last study visit, HIV-1 plasma viral load was $>50$ copies $/ \mathrm{mL}$ in $8.1 \%$ of patients, and the median CD4 count was 659 cells $/ \mathrm{mcL}$ (IQR, 444.2-999.7) (Table 1).

The families of antiretroviral drugs received by the patients at study completion were as follows: 1) $52.7 \%$ of 
Table I Demographic and clinical variables of HIV-positive patients aged $50-64$ years

\begin{tabular}{|c|c|c|}
\hline Variable & $\%(n)$ & $\begin{array}{l}\text { Median } \\
\left(\mathbf{P}_{25}-\mathbf{P}_{75}\right)\end{array}$ \\
\hline \multicolumn{3}{|l|}{ Sex } \\
\hline Male & $73.4(146)$ & \\
\hline Female & $26.6(53)$ & \\
\hline Age, years & & $52(5 I-56)$ \\
\hline $50-54$ & $66.8(133)$ & \\
\hline $55-59$ & $23.6(47)$ & \\
\hline $60-64$ & 9.5 (19) & \\
\hline Time since HIV diagnosis, years $(n=198)$ & & $18.0(10.1-24.0)$ \\
\hline$\leq 10$ & $27.3(54)$ & \\
\hline $\mathrm{II}-20$ & $34.8(69)$ & \\
\hline$>20$ & $37.9(75)$ & \\
\hline Time since ART initiation, years $(n=190)$ & & $14.7(8.2-18.0)$ \\
\hline$\leq 10$ & $33.7(64)$ & \\
\hline $1 \mathrm{I}-20$ & $51.6(98)$ & \\
\hline$>20$ & $14.4(28)$ & \\
\hline \multicolumn{3}{|l|}{ CD4 count, cells/mcL $(n=198)$} \\
\hline$<200$ & $3.5(7)$ & \\
\hline $200-350$ & I4.I (28) & \\
\hline $35 I-500$ & $15.6(31)$ & \\
\hline$>500$ & $66.7(132)$ & \\
\hline \multicolumn{3}{|l|}{ VL, copies/mL ( $\mathrm{n}=198)$} \\
\hline$<50$ & $91.9(182)$ & \\
\hline $50-200$ & $3.0(6)$ & \\
\hline$>200$ & $5.1(10)$ & \\
\hline
\end{tabular}

Abbreviations: ART, antiretroviral therapy; HIV, human immunodeficiency virus; VL, viral load.

patients were treated with protease inhibitors, specifically, darunavir, lopinavir, and atazanavir, at 36.2\%, 9.5\%, and $7.0 \%$, respectively; 2 ) $47.7 \%$ of patients received a nonnucleotide reverse transcriptase inhibitor, specifically etravirine, nevirapine, efavirenz, and rilpivirine, at 18.1\%, 12.1\%, $11.6 \%$, and $6.0 \%$, respectively; 3 ) $73.4 \%$ were treated with a nucleoside reverse transcriptase inhibitor, specifically, tenofovir disoproxil fumarate/emtricitabine, abacavir/lamivudine, lamivudine, and tenofovir disoproxil fumarate, at $38.7 \%$, $32.7 \%, 1.0 \%$, and $1.0 \%$, respectively; 4) $19.6 \%$ were treated with an integrase inhibitor, all with raltegravir; and 5) $1.5 \%$ received a CCR5 receptor antagonist, all with maraviroc.

\section{Comparison of number of concomitant medications (not ART)}

The median number of concomitant medications received was higher in HIV-positive males than in males from the general population (4 IQR [1-8] vs 2 IQR [0-5]; $P<0.001$ ).

The proportion of patients collecting at least one concomitant medication during the study year was higher in HIV-positive males than in males from the general population ( $80.1 \%$ vs $70.7 \%$ for any drug, $P=0.013 ; 58.9 \%$ vs $48.8 \%$ for drugs with a DDD $>90, P=0.016$; and $48.6 \%$ vs $40.3 \%$ for drugs with DDD $>180, P=0.043)$. Long-term polypharmacy ( $\geq 5$ non-ART drugs) was more common in the HIV-positive males than in males from the general population for drugs with a DDD $>90(13.0 \%$ vs $8.8 \%$ of males, $P=0.079)$ and a DDD $>180(8.9 \%$ vs $4.4 \%, P=0.010)$ (Figure $1 \mathrm{~A})$.

Of the $53 \mathrm{HIV}$-positive females and the 2,176 females from the general population, $84.9 \%$ and $80.1 \%$, respectively $(P=0.382)$ collected at least one concomitant medication during the study year, and $47.2 \%$ and $40.4 \%(P=0.321)$ collected five or more. However, when long-term treatments were considered, a higher proportion of HIV-positive females than females from the general population were polymedicated $(\geq 5$ non-ART drugs), collecting drugs with a DDD $>90(18.9 \%$ vs $9.8 \%, P=0.030)$ and drugs with a DDD $>180(11.3 \%$ vs $3.4 \%, P=0.002$ ) (Figure 1B).

\section{Therapeutic classes}

A statistically significant higher proportion of HIV-positive male patients than male patients from the general population received analgesics, anti-infectives, GI drugs, CNS agents, and respiratory drugs. There were no differences in the percentage of patients who received cardiovascular drugs. Similarly, there were no significant differences between HIV-positive females and female controls regarding the therapeutic classes of drug used (Figure 2).

On comparing therapeutic subgroups, HIV-positive males were significantly more likely than males from the general population to be taking the following drugs: drugs for acid-related disorders (A02) $32.2 \%$ vs $24.1 \%, P=0.024$; $\beta$-blocking agents (C07) $11.6 \%$ vs $6.8 \%, P=0.022$; antibacterials for systemic use (J01) $47.9 \%$ vs $24.0 \%, P<0.001$; analgesics (N02) 41.1\% vs 23.7\%, $P<0.001$; antiepileptics (N03) $12.3 \%$ vs 5.1\%, $P<0.001$; psycholeptics (N05) $31.5 \%$ vs $16.0 \%, P<0.001$; psychoanaleptics (N06) $13.0 \%$ vs $7.0 \%, P<0.001$; drugs for obstructive airway disease (R03) $13.0 \%$ vs $6.2 \%, P=0.001$; and antihistamines for systemic use (R06) $15.8 \%$ vs $9.1 \%, P=0.006$.

One of the main differences in the therapeutic subgroups used between HIV-positive patients and the general population was the use of anti-infectives; therefore, a more detailed analysis of this was performed. A higher percentage of HIV-positive males than males from the general population received antibiotics from the groups sulfonamides and trimethoprim $(17.1 \%$ vs $1.5 \%, P<0.001)$; quinolones (34.3\% vs $21.2 \%, P=0.009)$; and macrolides, lincosamides, and streptogramins $(37.1 \%$ vs $24.9 \%, P=0.020)$. This increased consumption was mainly due to a higher percentage of HIV-positive males than males from the general population using cotrimoxazole $(17.1 \%$ vs $1.5 \%, P<0.001)$, 

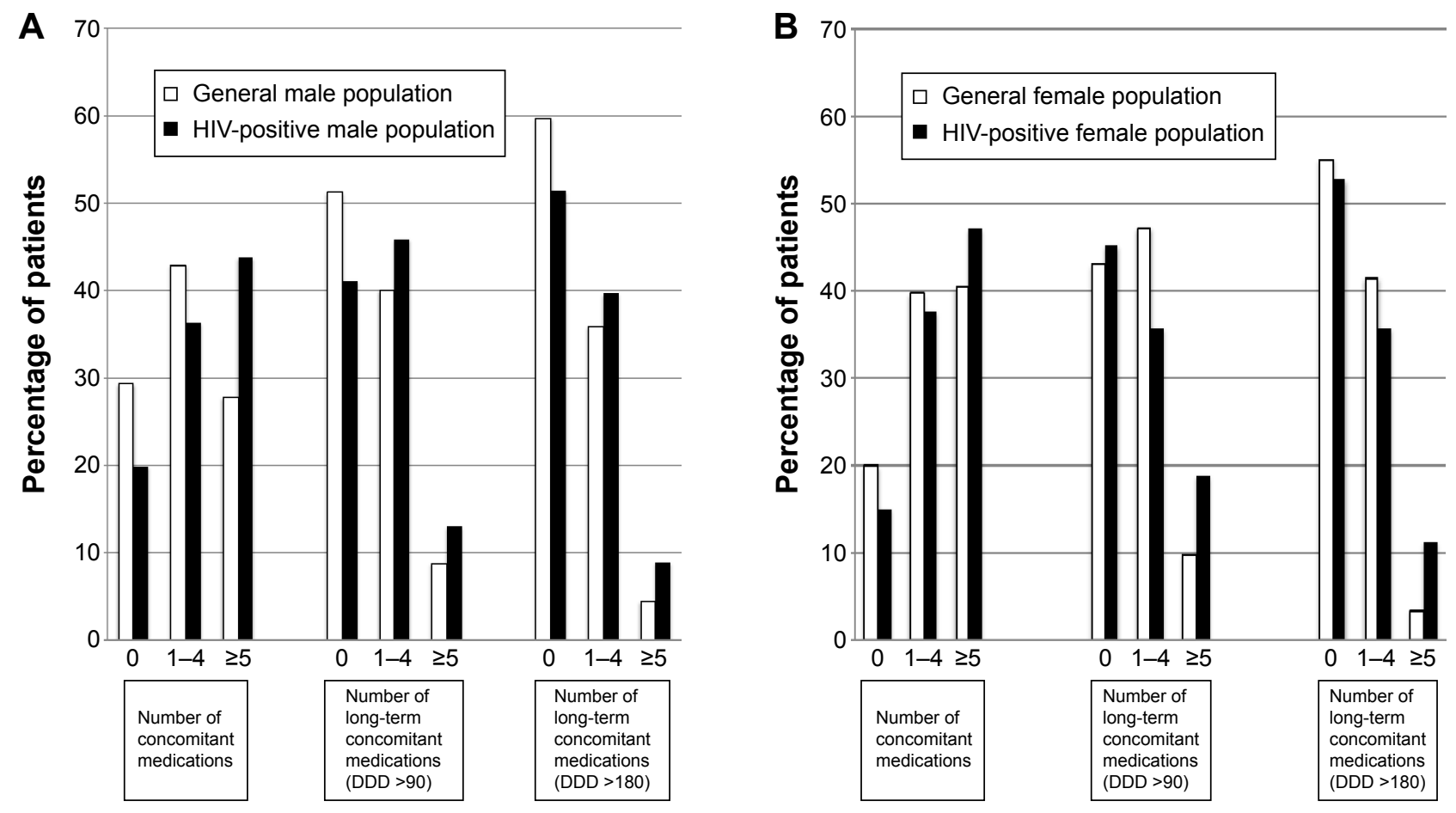

Figure I Concomitant medication use in HIV-positive patients and general population, aged 50-64 years.

Notes: (A) Males, (B) females. Use of $0,1-4$, and $\geq 5$ prescribed concomitant medications (excluding antiretrovirals) was calculated according to I) drugs with a DDD $>$ I; 2) drugs with a DDD $>90$ (treatments lasting $>90$ days); and 3 ) drugs with a DDD $>180$ (treatments lasting $>180$ days).

Abbreviations: DDD, defined daily dose; HIV, human immunodeficiency virus.

azithromycin $(34.3 \%$ vs $20.4 \%, P=0.005)$, levofloxacin (15.7\% vs $5.2 \%, P<0.001)$, and moxifloxacin $(11.4 \%$ vs $5.1 \%, P=0.020)$.

Based on median DDDs, treatment duration was significantly longer in HIV-positive males than in males from the general population for anti-infectives (32.2 vs 20.0 DDDs,
$P<0.001)$ and CNS agents (238.7 vs 120.0 DDDs, $P=0.002$ ). In HIV-positive females, treatment duration was significantly longer than in females from the general population for CNS agents (471.0 vs 140.0 DDDs, $P=0.003$ ), respiratory drugs (83.1 vs 45.0 DDDs, $P=0.045$ ), and GI drugs (364.0 vs 121.3 DDDs, $P=0.022$ ) (Figure 3 ).

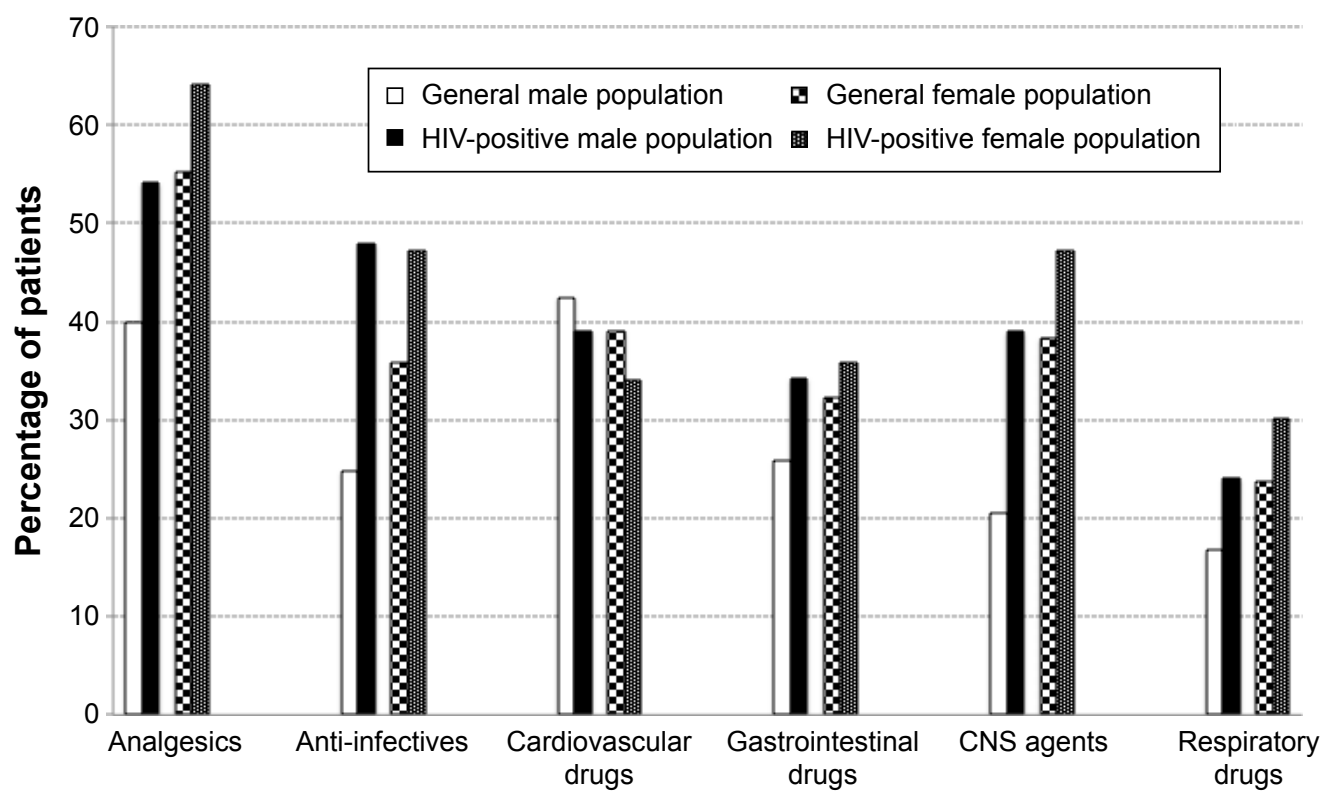

Figure 2 Use of concomitant medication by therapeutic class and sex, in HIV-positive patients and general population, aged 50-64 years. Abbreviations: CNS, central nervous system; HIV, human immunodeficiency virus. 


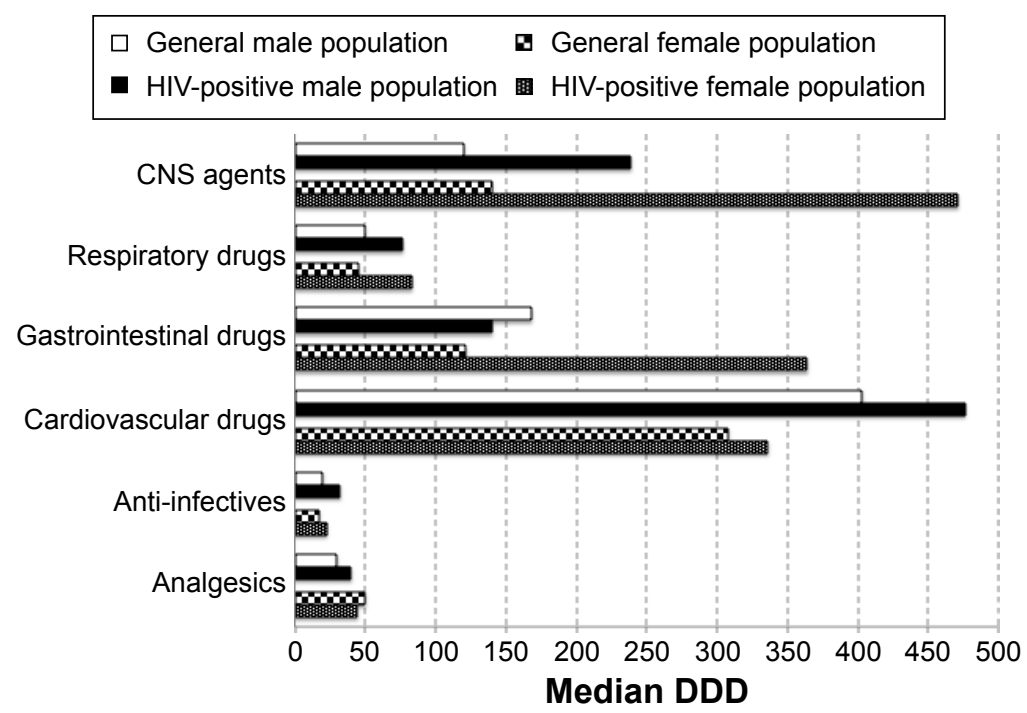

Figure 3 Median days of treatment duration per patient (based on DDD), by therapeutic class and sex, over a I-year period, in HIV-positive patients and general population, aged 50-64 years.

Note: Treatment duration was calculated using the median of sum of the DDDs for each medication within each therapeutic class. Abbreviations: CNS, central nervous system; DDD, defined daily dose; HIV, human immunodeficiency virus.

Treatment duration (median DDDs) was also significantly longer in the HIV-positive males than in males from the general population for antithrombotic agents (B01) (330.0 vs $270.0, P=0.014)$, lipid-modifying agents (C10) (308.0 vs 205.3, $P=0.031)$, antibacterials for systemic use (J01) (27.7 vs $20.0, P=0.001)$, and antipsycholeptics (N05) (177.5 vs $60.0, P=0.001)$.

\section{Discussion}

We found a significantly higher prevalence of polypharmacy in the HIV group than in the general population, for both males and females. A higher proportion of HIV-positive patients received analgesics, anti-infectives, GI drugs, CNS agents, and respiratory drugs than in the general population. Cardiovascular drugs were used to a similar extent in both populations. The higher use of antibiotics in HIV-positive patients was due to sulfamethoxazole and trimethoprim, azithromycin, levofloxacin, and moxifloxacin use.

Previous studies have shown differences in the use of concomitant medications and therapeutic drug classes between older and younger HIV-positive patients. ${ }^{16,17,19}$ Our study published in $2015^{23}$ also compared concomitant medication usage between HIV-positive individuals and the general population, but the present study adds several aspects to this. This study has a larger number of HIV-positive patients, increased from 130 in 2011 to 199 in 2014. Therefore, we were able to expand the comparative analysis of concomitant medication use in males in 2011, to perform it in females - a minority population in all HIV studies - in 2014. In addition, the population for comparison is a sample of the general population that is more similar in age and sex to the HIV population than in the previous study. Furthermore, drugs were grouped by organ or system, so that a more global analysis of their use could be performed.

The proportion of HIV-positive patients who collected five or more non-ART medications in our study is slightly lower than previously reported rates $(43.8 \%$ and $47.2 \%$ for males and females, respectively, in our study compared with $54.0 \%$ and $57.6 \%$ for both sexes in other studies). ${ }^{17,23}$ This difference could be due to the fact that, unlike other studies, we did not include alternative treatments. When long-term treatments (those with $>90$ or $>180$ DDDs) were taken into account, differences in polypharmacy prevalence were even greater at $13.0 \%$ and $8.9 \%$ for HIV-positive males and $18.9 \%$ and $11.3 \%$ for HIV-positive females. This may be due to differences in the methods used to calculate drug consumption and differences in the types of study performed, that is, previous cross-sectional studies versus our long-term study. While other studies used clinical notes and/or patient self-reporting, our study analyzed what patients actually collected from pharmacies. There is, of course, a risk that patients might not actually take their medications, but we believe that this method provides a more accurate picture of actual drug consumption. ${ }^{29,30}$

Use of analgesics, anti-infectives, GI drugs, CNS agents, and respiratory drugs was greater in the HIV-positive population than in the general population. The differences were statistically significant for males but not for females; this 
was probably because females were underrepresented in this HIV population. The findings of this study were consistent with previous findings by our group, which showed no differences between the percentage of HIV-positive males and males from the general population receiving cardiovascular drugs such as renin-angiotensin inhibitors or lipid-lowering drugs. ${ }^{23}$ In the present study, there were no differences in cardiovascular drug use between the two populations compared, independently of sex. The percentage of HIV-positive individuals receiving cardiovascular drugs in our study $(39 \%$ of males and $34 \%$ of females) was lower than previous findings (53\% and $65 \%$, respectively). ${ }^{16,19}$ The results on cardiovascular drugs use were unexpected because cardiovascular disease is more prevalent in HIV-positive patients than in similarly aged members of the general population. ${ }^{9,11}$ Possible explanations include underdiagnosis of cardiovascular disease in these patients, or lower rates of primary and secondary cardiovascular prophylaxis. It has been reported that only one of every five patients with HIV who are candidates for receiving aspirin as primary cardiovascular prophylaxis receive this treatment. ${ }^{31}$ Furthermore, a lower proportion of HIV-positive patients receive this prophylaxis compared with the HIV-negative population. ${ }^{32}$ In addition, it has been shown that a lower percentage of HIV-positive patients compared with HIV-negative patients receive lipid-lowering therapy, irrespective of the presence of cardiovascular disease. ${ }^{33}$ However, in the absence of better data, we cannot offer a definitive explanation for this.

In accordance with earlier findings by our group, ${ }^{23}$ regarding the percentage of patients who received certain drugs, the most notable differences were found for anti-infectives and CNS drugs. The higher rate of prescription of CNS drugs in HIV-positive patients can probably be explained by a higher prevalence of psychiatric disease, substance abuse, and drug dependence among HIV-positive individuals. ${ }^{34,35}$ Despite good immunological control of HIV infection, antibiotics were prescribed to a considerably higher proportion of the HIV population $(47.9 \%$ of males and $47.2 \%$ of females) than the general population $(24.8 \%$ of males and $35.8 \%$ of females). A higher percentage of HIV-positive males were treated with trimethoprim/sulfamethoxazole, azithromycin, levofloxacin, and moxifloxacin. In the HIV population, cotrimoxazole is most commonly used as primary prophylaxis against Pneumocystis jirovecii in severely immunocompromised patients, as secondary prophylaxis in patients with previous $P$. jirovecii pneumonia, and as primary prophylaxis against Toxoplasma gondii. ${ }^{36}$ There is no obvious explanation for the higher use of azithromycin, levofloxacin, and moxifloxacin in HIV-positive patients; it could be due to more empirical and/or earlier use than in the general population, owing to the immunosuppressive nature of the infection, despite good CD4 levels. These antibiotics are first line for respiratory infections, which are very common in the primary care setting. To this, we can add the probable use of antibiotics dispensed from pharmacies without a physician's prescription, which, consequently, could not be included in this analysis. ${ }^{37}$

Compared with the general population, HIV-positive patients had longer durations of drug use, as defined by median DDDs (due to either the number of treatment days or higher doses). The differences were statistically significant for CNS agents (males and females), anti-infectives (males), and respiratory drugs (females) and GI drugs (females). Longer treatment with anti-infectives and CNS agents is consistent with previous findings by our group. ${ }^{23}$ The median DDD of CNS agents received per year by males with HIV was double than in males from the general population (238 vs $120, P=0.002)$. This indicates that these drugs are used at a higher dose and for a longer time than in the general population. Regarding anti-infectives, the median DDD consumed by HIV-positive males was also higher than that for the general population $(32.2$ vs $20.0, P<0.001)$. As these treatments were for acute illnesses, this indicates either that there were a greater number of acute illnesses in the study year, or that the doses used were higher.

One strength of this study is that we measured drug consumption, unlike previous studies that have provided figures based on clinical notes and patient self-reporting. ${ }^{16,18-20}$ Some studies distinguish between "polyprescription" (what the physician prescribes) and "polytherapy" (what the patient actually takes). ${ }^{38}$ As mentioned, we believe that pharmacydispensed prescriptions provide a more accurate picture of actual drug use than physician prescriptions, because there can be differences between what is recorded in the clinical records (which can be split between the hospital and primary care), what the patients say they are taking (with possible omissions and errors), and what is actually collected from the pharmacy. Although collection from the pharmacy does not mean that the patient adheres correctly to treatment, clearly they cannot take a medication if it has not been collected from the pharmacy first. Another strength of this study is that we performed a sex-stratified analysis and compared our findings with a sample of the general population with same age and sex distribution.

A common limitation of studies that analyze pharmacydispensed drug consumption is that they include data only on 
drugs covered by official medical prescriptions, that is, they do not include private health care treatments or alternative medicines. However, we do not believe that this is a significant limitation in this study, as public health care coverage is universal in Spain. This study was conducted in a single hospital; therefore, the results have a limited generalizability. Likewise, the number of HIV-positive patients was small, with very few females, thus limiting the conclusions that can be drawn from the comparisons performed. This is a common limitation, due the low percentage of female HIV-positive patients in our setting.

It would be useful to expand this analysis to a larger population, involving several hospitals, to be able to validate these data. Likewise, a study on the appropriate use of CV drugs in the HIV-positive population would be worthwhile.

To reduce the risk of polypharmacy, the HIV and Aging Consensus Project recommends that clinicians managing older adults with HIV infection compile an accurate list of medications. In order to do so, they recommend patients use a single pharmacy, a pharmacy with an integrated computer network, or an HIV-specialized pharmacy. Involving a clinical pharmacist can also help to reduce inappropriate prescribing and drug-related problems. ${ }^{7}$ Similar recommendations were made by the GESIDA (Study Group of AIDS) expert panel. ${ }^{8}$

Our study revealed a higher prevalence of polypharmacy in HIV-positive patients aged 50-64 years compared with members of the general population of the same age and sex. The greater use of non-ART drugs suggests a higher prevalence of comorbidity in this population. This highlights the need for close monitoring and regular medication review to ensure the timely detection of possible adverse events, selective adherence, drug-drug interactions, and potentially inappropriate medication, particular care should be taken with cardiovascular medications and anti-infectives.

\section{Acknowledgments}

The authors gratefully acknowledge Eva Guarc and Violeta Alastrué for their help with data queries and Cristina Feja for her help calculating the general population sample size.

\section{Disclosure}

The authors report no conflicts of interest in this work.

\section{References}

1. Lohse N, Hansen A, Pedersen G, et al. Survival of persons with and without HIV infection in Denmark 1995-2005. Ann Intern Med. 2007; 146(2):87-95.

2. Blanco JR, Caro AM, Pérez-Cachafeiro S, et al. HIV infection and aging. AIDS Rev. 2010;12(4):218-230.
3. Dirección General de Salud Pública, Calidad e Innovación. Informe de Evaluación. Plan Multisectorial de VIH-SIDA. 2008-2012. Actualización a Diciembre de 2013 con datos epidemiológicos de 2012. [Public Health Department, Quality and Innovation. Evaluation report. Multisectorial AIDS Plan. 2008-2012. December 2013 update with epidemiological data of 2012]. Madrid: Ministerio de Sanidad Servicios Sociales e Igualdad; 2013. Available from: https://www.msssi.gob.es/ ciudadanos/enfLesiones/enfTransmisibles/sida/docs/informeEvaluacion30Agosto2013.pdf. Accessed December 1, 2015.

4. Ray M, Logan R, Sterne JA, et al; HIV-CAUSAL Collaboration. The effect of combined antiretroviral therapy on the overall mortality of HIV-infected individuals. AIDS. 2010;24(1):123-137.

5. Samji H, Cescon A, Hogg RS, et al. Closing the gap: increases in life expectancy among treated HIV-positive individuals in the United States and Canada. PLoS One. 2013;8(12):6-13.

6. Smit M, Brinkman K, Geerlings S, et al. Future challenges for clinical care of an ageing population infected with HIV: a modelling study. Lancet Infect Dis. 2015;15(7):810-818.

7. Work Group for The HIV and Aging Consensus Project. Summary report from the human immunodeficiency virus and aging consensus project: treatment strategies for managing older individuals with human immunodeficiency virus. J Am Geriatr Soc. 2012;60(5):974-979.

8. Grupo de expertos de la Secretaría del Plan Nacional sobre el SIDA (SPNS), Sociedad Española de Geriatría y Gerontología (SEGG). Documento de consenso sobre edad avanzada e infección por el virus de la inmunodeficiencia humana (Noviembre 2015). [Expert Group of National AIDS Plan (SPNS), Spanish Society of Geriatrics and Gerontology (SEGG). Consensus Document on Elderly and Infection of HIV (November 2015)]. Madrid: Ministerio de Sanidad Servicios Sociales e Igualdad; 2015. Available from: http://www.msssi.gob.es/ ciudadanos/enfLesiones/enfTransmisibles/sida/publicaciones/profSanitarios/docEdadAvanzadaVIH.pdf. Accessed December 1, 2015.

9. Guaraldi G, Orlando G, Zona S, et al. Premature age-related comorbidities among HIV-infected persons compared with the general population. Clin Infect Dis. 2011;53(11):1120-1126.

10. Panel on Antiretroviral Guidelines for Adults and Adolescents. Guidelines for the Use of Antiretroviral Agents in HIV-1-Infected Adults and Adolescents. Department of Health and Human Services. [Internet]; 2016. Available from: http://aidsinfo.nih.gov/contentfiles/lvguidelines/ AdultandAdolescentGL.pdf. Accessed January 1, 2016.

11. Schouten J, Wit FW, Stolte IG, et al. Cross-sectional comparison of the prevalence of age-associated comorbidities and their risk factors between HIV-infected and uninfected individuals: the AGEhIV cohort study. Clin Infect Dis. 2014;59(12):1787-1797.

12. Edelman EJ, Gordon KS, Glover J, McNicholl IR, Fiellin DA, Justice AC. The next therapeutic challenge in HIV: polypharmacy. Drugs Aging. 2013;30(8):613-628.

13. Cantudo-cuenca MR, Jiménez-Galán R, Almeida-González CV, Morillo-Verdugo R. Concurrent use of comedications reduces adherence to antiretroviral therapy among HIV-infected patients. $J$ Manag Care Pharm. 2014;20(8):844-850.

14. Nachega JB, Hsu AJ, Uthman OA, Spinewine A, Pham PA. Antiretroviral therapy adherence and drug-drug interactions in the aging HIV population. AIDS. 2012;26(Suppl 1):S39-S53.

15. Gleason LJ, Luque AE, Shah K. Polypharmacy in the HIV-infected older adult population. Clin Interv Aging. 2013;8:749-763.

16. Marzolini C, Back D, Weber R, et al. Ageing with HIV: medication use and risk for potential drug-drug interactions. J Antimicrob Chemother. 2011;66(9):2107-2111.

17. Holtzman C, Armon C, Tedaldi E, et al; the HOPS Investigators. Polypharmacy and risk of antiretroviral drug interactions among the aging hiv-infected population. J Gen Intern Med. 2013; 28(10):1302-1310.

18. Greene M, Steinman M, McNicholl I, Valcour V. Polypharmacy, drugdrug interactions, and potentially inappropriate medications in older adults with human immunodeficiency virus infection. J Am Geriatr Soc. 2014;62(3):447-453. 
19. Tseng A, Szadkowski L, Walmsley S, Salit I, Raboud J. Association of age with polypharmacy and risk of drug interactions with antiretroviral medications in HIV-positive patients. Ann Pharmacother. 2013;47(11): 1429-1439.

20. Marzolini C, Elzi L, Gibbons S, et al. Prevalence of comedications and effect of potential drug-drug interactions in the Swiss HIV cohort study. Antivir Ther. 2010;15(3):413-423.

21. Schmiemann G, Bahr M, Gurjanov A, Hummers-Pradier E. Differences between patient medication records held by general practitioners and the drugs actually consumed by the patients. Int J Clin Pharmacol Ther. 2012;50(8):614-617.

22. Furler M, Einarson T, Walmsley S, Millson M, Bendayan R. Polypharmacy in HIV: impact of data source and gender on reported drug utilization. AIDS Patients Care STDS. 2004;18(10):568-586.

23. Gimeno-Gracia M, Crusells-Canales MJ, Javier Armesto-Gómez F, Rabanaque-Hernández MJ. Prevalence of concomitant medications in older HIV+ patients and comparison with general population. HIV Clin Trials. 2015;16(3):117-124.

24. Núñez Montenegro AJ, Montiel Luque A, Martín Aurioles E, Torres Verdú B, Lara Moreno C, González Correa JA; en representación del grupo Polipresact. Adherencia al tratamiento en pacientes polimedicados mayores de 65 años con prescripción por principio activo. [Adherence to treatment, by active ingredient, in patient over 65 years on multiple medication]. Atención Primaria. 2014;46(5):238-245.

25. Garrido-Garrido EM, García-Garrido I, García-López-Durán JC, García-Jiménez F, Ortega-López I, Bueno-Cavanillas A. Estudio de pacientes polimedicados mayores de 65 años en un centro de asistencia primaria urbano. [Study of polymedicated patients over 65 years-old in an urban primary care centre]. Rev Calid Asist. 2011;26(2):90-96.

26. Richardson K, Ananou A, Lafortune L, Brayne C, Matthews FE. Variation over time in the association between polypharmacy and mortality in the older population. Drugs Aging. 2011;28(7):547-560.

27. Gnjidic D, Hilmer SN, Blyth FM, et al. Polypharmacy cutoff and outcomes: five or more medicines were used to identify communitydwelling older men at risk of different adverse outcomes. J Clin Epidemiol. 2012;65(9):989-995.

28. WHO Collaborating Centre for Drug Statistics Methodology. ATC/ DDD Classification Index with DDDs. Oslo; 2015. Available from: http://www.whocc.no/atc_ddd_index/. Accessed June 1, 2015.

29. Malo S, Rabanaque MJ, Feja C, Lallana MJ, Aguilar I, Bjerrum L. High antibiotic consumption: a characterization of heavy users in Spain. Basic Clin Pharmacol Toxicol. 2014;115(3):231-236.
30. Malo-Fumanal S, Rabanaque-Hernández MJ, Feja-Solana C, LallanaAlvarez MJ, Armesto-Gómez J, Bjerrum L. Diferencias en el uso extrahospitalario de antibióticos entre una región española y un país nórdico. [Differences in outpatient antibiotic use between a Spanish region and a Nordic country]. Enferm Infecc Microbiol Clin. 2014;32(7):412-417.

31. Burkholder GA, Tamhane AR, Salinas JL, et al. Underutilization of aspirin for primary prevention of cardiovascular disease among HIVinfected patients. Clin Infect Dis. 2012;55(11):1550-1557.

32. Suchindran S, Regan S, Meigs J, Grinspoon S, Triant V. Aspirin use for primary and secondary prevention in human immunodeficiency virus (HIV)-infected and HIV-uninfected patients. Open Forum Infect Dis. 2014;1(3):ofu076.

33. Freiberg MS, Leaf DA, Goulet JL, et al. The association between the receipt of lipid lowering therapy and HIV status among veterans who met NCEP/ATP III criteria for the receipt of lipid lowering medication. J Gen Intern Med. 2009;24(3):334-340.

34. Goulet JL, Fultz SL, Rimland D, et al. Aging and infectious diseases: do patterns of comorbidity vary by HIV status, age, and HIV severity? Clin Infect Dis. 2007;45(12):1593-1601.

35. Justice AC, McGinnis KA, Atkinson JH, et al. Psychiatric and neurocognitive disorders among HIV-positive and negative veterans in care: Veterans Aging Cohort Five-Site Study. AIDS. 2004; 18(Suppl 1):S49-S59.

36. Grupo de estudio del SIDA-SEIMC. Documento de prevención y tratamiento de infecciones oportunistas y otras coinfecciones en pacientes con infección por VIH. [Study Group of AIDS. Document of Prevention and Treatment of Opportunistic Infections and other co-infections in HIV-positive patients]. Madrid; 2015. Available from: http://www.gesida-seimc.org/contenidos/guiasclinicas/2015/gesidaguiasclinicas-2015-InfeccionesOportunistasyCoinfeccionesVIH.pdf. Accessed February 1, 2016.

37. Zapata-Cachafeiro M, González-González C, Váquez-Lago JM, et al. Determinants of antibiotic dispensing without a medical prescription: a cross-sectional study in the north of Spain. JAntimicrob Chemother. 2014; 69(11):3156-3160.

38. Rollason V, Vogt N. Reduction of polypharmacy in the elderly: a systematic review of the role of the pharmacist. Drugs Aging. 2003 20(11):817-832.
Clinical Interventions in Aging

\section{Publish your work in this journal}

Clinical Interventions in Aging is an international, peer-reviewed journal focusing on evidence-based reports on the value or lack thereof of treatments intended to prevent or delay the onset of maladaptive correlates of aging in human beings. This journal is indexed on PubMed Central, MedLine,

\section{Dovepress}

CAS, Scopus and the Elsevier Bibliographic databases. The manuscript management system is completely online and includes a very quick and fair peer-review system, which is all easy to use. Visit http://www.dovepress. com/testimonials.php to read real quotes from published authors. 